\title{
Inheritance pattern of molar-incisor hypomineralization
}

\author{
Fabiano JEREMIAS(a) (D) \\ Diego Girotto BUSSANELI(a) \\ Manuel RESTREPO(b) (D) \\ Ricardo Augusto \\ Gonçalves PIERRI(a) \\ Juliana Feltrin de SOUZA(c) \\ Camila Maria Bullio FRAGELLI(a) \\ Rodrigo SECOLIN(d) (D) \\ Claudia Vianna \\ MAURER-MORELLI(e) \\ Rita de Cassia Loiola CORDEIRO(a) \\ Raquel Mantuaneli \\ SCAREL-CAMINAGA(a) \\ Lourdes SANTOS-PINTO(a) \\ (a) Universidade Estadual Paulista - UNESP, \\ school of Dentistry, Department of \\ Morphology, Genetics, Orthodontics and \\ Pediatric Dentistry, Araraquara, SP, Brazil. \\ (b) Universidade CES - Basic and Clinical \\ Research Group in Dentistry, School of \\ Dentistry, Medellín, Antioquia, Colombia. \\ (c) Universidade Federal do Paraná - UFPR, \\ School of Dentistry, Department of \\ Stomatology, Curitiba, PR, Brazil. \\ (d) Universidade Estadual de Campinas - \\ Unicamp, School of Medicine, Department \\ of Medical Genetics and Genomic \\ Medicine, Campinas, SP, Brazil. \\ (e) Universidade Estadual de Campinas - \\ Unicamp, School of Medical Science, \\ Department of Medical Genetics, \\ Campinas, SP, Brazil.
}

Declaration of Interests: The authors certify that they have no commercial or associative interest that represents a conflict of interest in connection with the manuscript.

\section{Corresponding Author:}

Lourdes Santos-Pinto'

E-mail: tukafoar@gmail.com

https://doi.org/10.1590/1807-3107bor-2021.vol35.0035

Submitted: April 20, 2020

Accepted for publication: September 21, 2020

Last revision: October 19, 2020
Abstract: The aim of this study was to investigate the segregation patterns of molar incisor hypomineralization $(\mathrm{MIH})$ in families, given the evidence that its etiology is influenced by genetics. Clinically, MIH may be detected in parents and/or siblings of MIH-affected children. Our study included children with at least one first permanent molar affected by MIH (proband) and their first-degree relatives (parents and siblings). The participants were examined clinically to detect $\mathrm{MIH}$, according to the European Academy of Paediatric Dentistry criteria (2003). A total of 101 nuclear families (391 individuals) were studied. Proband diagnosis was followed by MIH classification of the subject, his parents and siblings, as affected, unaffected, or unknown. Segregation analysis was performed using the multivariate logistic regression model of the Statistical Analysis for Genetic Epidemiology package, and segregation models (general transmission, environmental, major gene, dominant, codominant and recessive models). The Akaike information criterion (AIC) was used to evaluate the most parsimonious model. In all, 130 affected individuals, 165 unaffected individuals, and 96 unknown individuals were studied. Severe MIH was found in $50.7 \%$ of the cases. A segregation analysis performed for $\mathrm{MIH}$ revealed the following different models: environmental and dominance $(p=0.05)$, major gene $(p=0.04)$, codominant $(p=0.15)$ and recessive models $(p=0.03)$. According to the AIC values, the codominant model was the most parsimonious (AIC $=308.36$ ). Our results suggest that the codominant model could be the most likely for inheriting MIH. This result strengthens the evidence that genetic factors, such as multifactorial complex defect, influence $\mathrm{MIH}$.

Keywords: Inheritance Patterns; Genetics; Phenotype.

\section{Introduction}

Molar-incisor hypomineralization (MIH) is a specific enamel defect. It was defined in 2001 as a form of systemic hypomineralization that affects one or more permanent first molars, with or without permanent incisor involvement. ${ }^{1}$ The prevalence of $\mathrm{MIH}$ worldwide ranges from $2.4 \%$ to $44 \%{ }^{2,3,4,5,6,7,7,9}$ It is particularly difficult to treat children with MIH, especially when they have experienced recurrent episodes of tooth hypersensitivity, even without dentin exposure. ${ }^{5}$ 
The etiology of MIH remains unclear. . $^{10,11,12}$ However, there is evidence that $\mathrm{MIH}$ is a multifactorial disturbance. ${ }^{13,14}$ This hypothesis corroborates previous findings regarding the environmental factors contributing to $\mathrm{MIH} \cdot{ }^{15,16}$ Additionally, genetic factors may influence MIH. ${ }^{17}$ The authors have previously demonstrated that polymorphisms in genes responsible for enamel development are associated with MIH..$^{17,18,19}$ This is a rational result, given that the entire process of dental enamel formation is under genetic control, ${ }^{20}$ and suggests that genetic causes could be at least partly responsible for MIH development.

In addition to the potential influence of genetic factors on $\mathrm{MIH}$, familial aggregation of $\mathrm{MIH}$ is commonly observed in clinical practice, since parents and/or siblings of MIH patients are also affected. We observed that the genes in 101 nuclear families were related to amelogenesis, an association not usually investigated. Factors such as BMP4 (bone morphogenetic protein), DLX3 (distal-less), and FGFR1 (fibroblast growth factor) are associated with MIH susceptibility. ${ }^{18}$ This is further evidence of the genetic contribution to MIH. In brief, the authors believe that the potential pattern of transmission of MIH has not been well investigated.

Segregation analysis uses statistical models to determine whether the variation of a phenotype is consistent with a single locus, and/or rejects the hypothesis of non-transmission, and/or identifies the mode of inheritance. ${ }^{21}$ Identifying the heritability of a given condition is important for gaining a better understanding of how the disease process develops. It provides information on statistical power, needed to discover the genes related to a specific phenotype in family-based studies. ${ }^{22}$ Non-zero heritability is a condition that is needed but not sufficient for detection of the genes related to a phenotype of interest. ${ }^{23}$ In other words, it offers a "clue" toward the path to be followed in pursuit of a better understanding of the genetic background of $\mathrm{MIH}$.

Striving to provide information concerning the potential genetic transmission model of $\mathrm{MIH}$, the authors performed the first complex segregation analysis in a Brazilian sample comprising nuclear families of MIH-affected probands.

\section{Methodology}

This report was written following STROBE (Strengthening the Reporting of Observational Studies in Epidemiology) guidelines.

\section{Study design}

This cross-sectional family-based study was performed with $\mathrm{MIH}$-affected children and their nuclear family, comprising parents and/or siblings. Informed consent/assent was obtained from all participants and their parents. This study was approved by the research ethics committee of FOAr-UNESP under protocol number $45 / 10$, in compliance with the guidelines of the Declaration of Helsinki.

\section{Settings, participants and study size}

The study was conducted with children aged between 6 and 12 years, undergoing dental treatment at the Pediatric Dentistry Clinic of São Paulo State University in Araraquara (FOAr-UNESP), from March 2015 to December 2015, in the city of Araraquara, state of São Paulo, Brazil. The study included children who had at least one first permanent molar affected by MIH (proband) and their first-degree relatives (parents and siblings), who were also examined clinically for the presence of MIH. The exclusion criteria were parents with consanguinity, patients who had evidence of enamel hypoplasia, enamel development defects linked to a syndrome, amelogenesis imperfecta, dental fluorosis, dental trauma in a primary tooth, apical periodontitis in primary teeth, or use of a fixed appliance.

Analysis of a segregation model of $\mathrm{MIH}$ was based on this sample of MIH cases selected from a representative sample of a previous study. ${ }^{5}$ All the children (142) diagnosed with MIH in the previous study, as well as their parents and siblings, were invited to participate in the present study. At the end, the sample consisted of 101 family nuclei. The individuals who did not have $\mathrm{MIH}$, but who belonged to the same family were designated as the controls.

\section{Variables}

The primary outcome of this study was the MIH pattern of segregation. This segregation model 
seeks to explain the family aggregation of a given phenotypic characteristic diagnosed from the analysis of affected probands.

\section{Data sources and measurements}

The MIH phenotype (enamel opacity, enamel breakdown, atypical restoration) was classified based on clinical characteristics defined by the European Academy of Paediatric Dentistry (EAPD) in 2003. ${ }^{24}$ Parents and siblings who had MIH were classified as "affected," and those who did not have MIH were classified as "unaffected." The individuals who were not evaluated for reasons like absence, refusal, or death, and/or who had restored or missing MIH index teeth that could compromise the clinical diagnosis, were classified as "unknown." For example, if the proband presented an enamel opacity and the relative presented an atypical restoration, both were classified as "affected." The visual examination of probands and their relatives was carried out in a dental office by two calibrated examiners (F.J. and C.M.B.F.), using artificial light, mouth mirror number 5 and gauze. Clinical records and heredograms (Figure 1) were stored in individual files.

The calibration process was carried out as follows: first, a principal investigator (L.S.P.) with experience in enamel development defects presented the criteria for MIH detection to F.J. and C.M.B.F., showed clinical photographs of teeth representing different EAPD index criteria, and discussed each of these situations in a session that lasted one to two hours. Next, they examined 20 subjects with or without MIH and discussed each case. The intraexaminer agreement was assessed by a second clinical examination in 10\% of the sample after two weeks, with a kappa coefficient of 0.95 . The interexaminer agreement was 0.93 .

\section{Statistical and segregation analysis}

Descriptive variables were analyzed by frequency and proportion, and categoric variables, by central tendency and dispersion statistical analyses. The segregation analysis was performed using a multivariate logistic regression model of the Statistical Analysis for Genetic Epidemiology package (SAGE) (Case Western Reserve University, Cleveland, USA). The genetic component and the mode of inheritance of MIH in this model was characterized by classifying individuals according to their disease status of either affected or unaffected. Therefore, the individual carrier types were considered $a a, a b$ and $b b$. The assumptions made were that the major locus has two alleles $(\mathrm{A}, \mathrm{a})$, and that the genotype frequencies follow the Hardy-Weinberg equilibrium. A logistic regression model was adjusted to describe the effects of these factors and cofactors, and the risk of disease was modeled mathematically.

Seven parameters were estimated, including the regression coefficients for genotypes, allele frequencies and transmission probabilities, which were analyzed for the Mendelian pattern of transmission from parents to offspring. These parameters $\left(\tau_{\mathrm{aa}}, \tau_{\mathrm{ab}}\right.$ and $\left.\tau_{\mathrm{bb}}\right)$ denote the probabilities of transmitting allele $a$ to genotypes $a a, a b$ and $b b$, respectively. Under Mendelian transmission, $\tau_{\mathrm{aa}}=1, \tau_{\mathrm{ab}}=0.5, \tau_{\mathrm{bb}}=0$ and no transmission, $\tau_{\mathrm{aa}}=\tau_{\mathrm{b}}=\tau_{\mathrm{bb}}$.

Segregation models (general transmission, environmental, major gene, dominant, codominant,

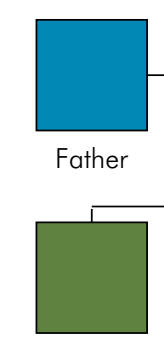

Affected child (proband)

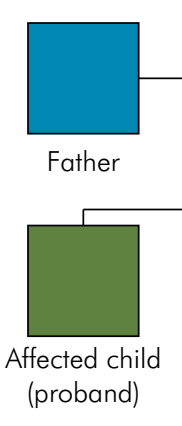

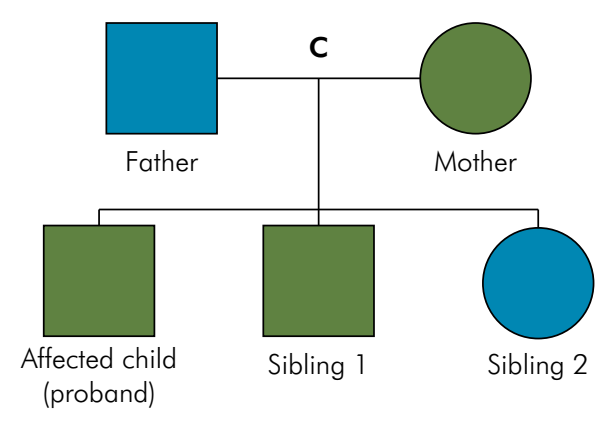

Figure 1. Pedigrees of proband families. (A) Only one affected member (proband); (B) Two affected members (proband and mother); (C) Three affected members (proband, mother and one sibling). 
and recessive models) were estimated by maximizing the conditional likelihood (L) of nuclear family phenotypes. This test was used to select the most parsimonious model, by making a comparison of strictly hierarchical models. The difference between -2lnL under a general model with $\mathrm{m}$ parameters and the segregation model with $\mathrm{n}$ parameters is $\chi^{2}$ asymptotically distributed, with $\mathrm{m}-\mathrm{n}$ degrees of freedom. The tested model was accepted when the p-value $>0.05$. In addition, the Akaike information criterion (AIC) ${ }^{25}$ (main factor in this analysis) was used for each model, which is -2lnL plus twice the number of free parameters in the model. This comparison has the advantage that one model does not have to be a subset of the other. The model with the lowest AIC was considered the most parsimonious fit for the data.

\section{Results}

The sample of this study comprised 101 nuclear families (391 individuals). The mean number of individuals affected per family was $1.28(\mathrm{~min}=1$, $\max =4)$. There were $79(78.2 \%)$ nuclear families with only one MIH-affected individual, and 22 (21.8\%) with two or more MIH-affected individuals, including siblings and parents. In all, there were 130 affected individuals, 165 unaffected individuals, and 96 unknown individuals.

Among the affected individuals $(\mathrm{n}=130) 50.4 \%$ were female. Among the unaffected individuals $(n=165), 42.7 \%$ were male and $57.3 \%$ were female. In $50.7 \%$ of the affected individuals, the MIH was considered severe. This means that the child had at least one tooth with structural loss or atypical restoration, or both clinical conditions (Figure 2). A total of $10 \%$ of the parents showed MIH (only a mild case). The three most common pedigrees of the proband families are presented in Figure 1.

According to the results of the segregation analysis (Table), the environmental ( $p=0.05)$, the Mendelian dominance $(p=0.05)$ and the Mendelian codominant models $(p=0.15)$ may have fit the sample, although the environmental and dominant models were at the limit of the $p$ value. However, according to the AIC
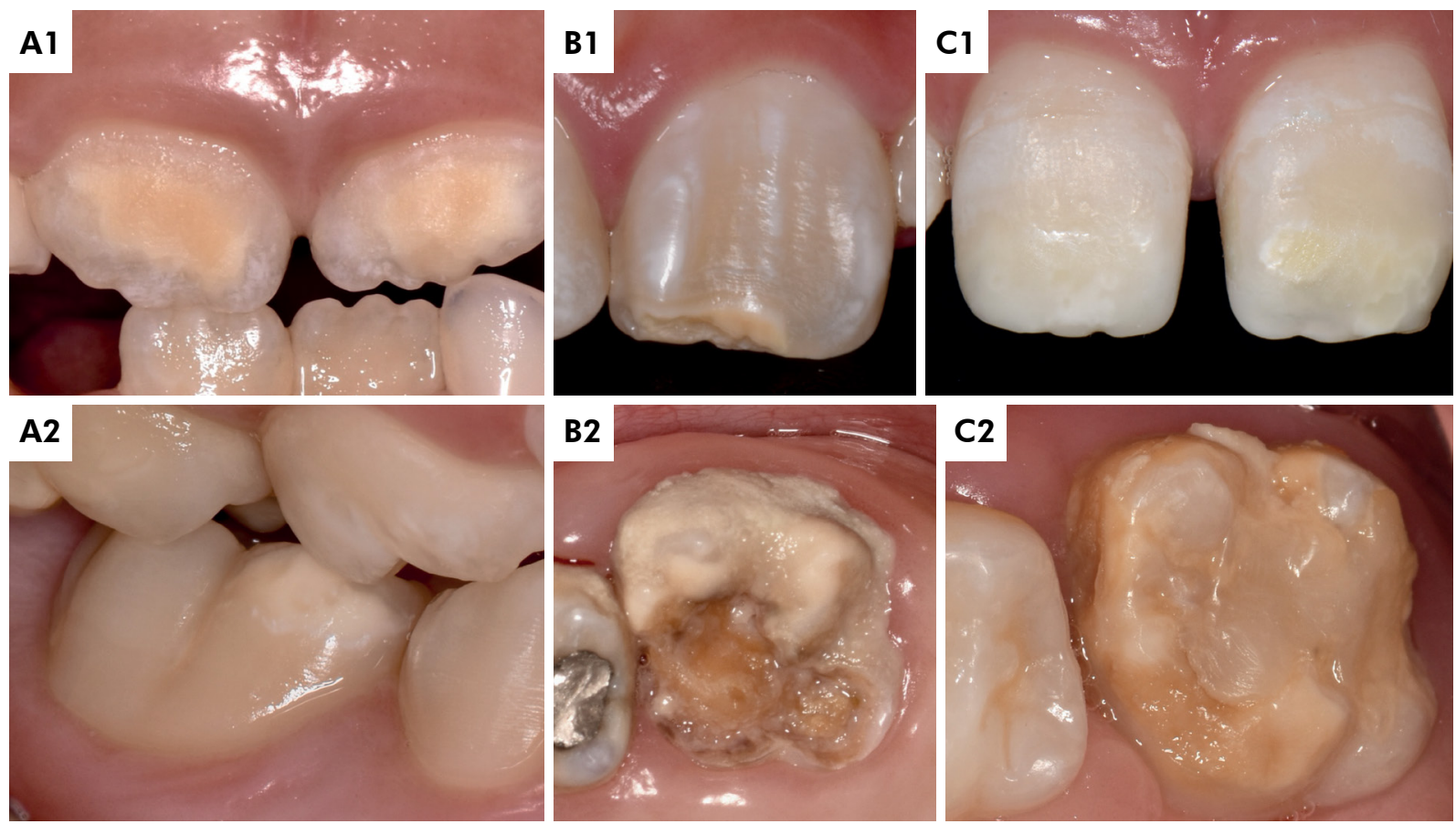

Figure 2. Clinical appearance of Molar-Incisor Hypomineralization. Demarcated opacities on buccal surface represent mild defects in permanent incisors (A1) and first permanent molars (A2); structural loss associated with opacities in incisors (B1) and a molar (B2); atypical restoration of permanent incisors $(\mathrm{C} 1)$ and first permanent molars (C2). Figures $B$ and $C$ depict severe defects. The photos are courtesy of Dr. Restrepo (Universidad CES). 
Table. Results of the segregation analysis performed for MIH. Values within square brackets were adjusted for calculation purposes.

\begin{tabular}{lcccccccccccc}
\hline Model & $\beta \mathrm{aa}$ & $\beta \mathrm{ab}$ & $\beta \mathrm{bb}$ & $\mathrm{q}$ & $\tau 1$ & $\tau 2$ & $\tau 3$ & $-2 \operatorname{lnL}$ & LRT & $\mathrm{df}$ & $\mathrm{p}$-value & AIC \\
\hline General & 0.784 & -0.093 & -0.354 & 0.304 & 1.00 & 1.00 & 0.00 & 295.191 & - & - & & 305.191 \\
Environmental & 0.054 & $=\beta \mathrm{aa}$ & $=\beta \mathrm{aa}$ & {$[0.000]$} & {$[0.00]$} & {$[0.00]$} & {$[0.00]$} & 307.351 & 12.16 & 6 & 0.0585 & 311.351 \\
Major gene & 0.787 & -0.083 & -0.219 & 0.263 & {$[1.00]$} & {$[0.50]$} & {$[0.00]$} & 303.309 & 8.11 & 3 & 0.0436 & 313.309 \\
Dominant & 0.218 & $=\beta \mathrm{aa}$ & -0.172 & 0.160 & {$[1.00]$} & {$[0.50]$} & {$[0.00]$} & 304.481 & 9.29 & 4 & 0.0542 & 312.481 \\
Codominant & 0.510 & 0.141 & -0.227 & 0.239 & {$[1.00]$} & {$[0.50]$} & {$[0.00]$} & 300.365 & 5.17 & 3 & 0.1595 & 308.365 \\
Recessive & -0.167 & $=\beta \mathrm{bb}$ & 0.220 & 0.745 & {$[1.00]$} & {$[0.50]$} & {$[0.00]$} & 305.545 & 10.35 & 4 & 0.0349 & 313.545 \\
\hline
\end{tabular}

$\beta a a, \beta a b, \beta b b$ : susceptibility alleles; $a a$, ab and bb may lead to the disease; $q$ : frequency of allele $a ; \tau 1, \tau 2, \tau 3$ : transmission probability of the genotypes aa $(\tau 1), a b(\tau 2)$ and bb $(\tau 3)$; -2lnL: -2 times the log likelihood L; LRT: likelihood ratio test; $\mathrm{df}=$ degrees of freedom; AlC: Akaike information criterion.

(AIC $=308.36)$, the codominant transmission model was the most parsimonious of all the models tested. Another interesting observation was the hypothesis of the major gene model acting on the phenotype; this was rejected by the analysis. Moreover, the segregation analysis indicated that more than one gene may be involved in the MIH phenotype.

\section{Discussion}

Systemic and environmental risk factors have previously been associated with the development of the MIH condition. ${ }^{10}$ Interestingly, in spite of the evidence of MIH family aggregation and the involvement of genetic factors predisposing to $\mathrm{MIH}_{1}, 17,18,19,26$ there is no knowledge regarding the genetic heritage of MIH. Herein, we developed the first investigation to identify inheritance models of MIH.

Evidence of genetic association predisposing to MIH was demonstrated in both Brazilian and Turkish patients, in which polymorphisms in genes related to enamel development, such as $A M B N, E N A M$ and TFIP11 genes, were found to be statistically different from the controls. ${ }^{17}$ Polymorphisms in genes indirectly related to enamel mineralization have also been associated with $\mathrm{MIH}$, such as immune-response related genes $^{19}$ and vitamin $\mathrm{D}$ receptor genes, ${ }^{27}$ reinforcing the concept of a multifactorial etiology with the genetic component involved in this condition. In a genome-wide association study, ${ }^{26}$ a SNP located near the SCUBE1 gene (normally involved in vascular biology) was associated with MIH patients of European origin. This gene is potentially and indirectly related to tooth development and mineralization, since it is suggested that SCUBE proteins may interact with
BMP signaling molecules expressed in epithelial and mesenchymal regions of the developing tooth. In spite of the originality of the study, ${ }^{26}$ and the potential indirect relationship of the SCUBE1 gene with tooth enamel development, the study was underpowered and did not include a control group, or other family-members, particularly siblings.

A new insight into the development of hypomineralized enamel defects has been found in the context of a generation penetrance pattern. The pathogenesis mechanism of MIH is not yet fully understood, specifically whether MIH is influenced by a genetic factor. Nevertheless, it is important to evaluate the transmission pattern of this trait. The segregation analysis study represents an important step toward learning about the heritage of a condition. We used a complex segregation analysis herein to investigate the MIH inheritance pattern, and the magnitude of environmental and polygenic effects that could influence the final phenotype. All these inferred parameters can be used subsequently in linkage analyses, fine mapping, and other gene identification strategies related to the phenotype. ${ }^{28}$ Although the AIC values obtained in the present study indicated that the codominant model is the most probable pattern of inheritance of $\mathrm{MIH}$, our data could not determine the inheritance pattern exactly. In other words, the results of this complex segregation analysis suggested that more than one gene could be involved in the MIH phenotype, thus suggesting a complex genetic disease pattern. This finding corroborates that of three previous results that enrolled the same individuals, ${ }^{17,18,19}$ showing the association of MIH with genetic variations in genes potentially associated with tooth enamel formation. 
MIH could also be attributed to environmental factors. ${ }^{11,29}$ In other words, multifactorial MIH etiology can be explained, at least partly, by genetic variants in some genes responsible for enamel formation, but the environment may also have some influence. Additionally, the influence of epigenetic components in defining human phenotypic variation should be borne in mind. Formerly, epigenetics used to describe the way in which gene-environment and gene-gene interactions shaped a phenotype during development. However, today, epigenetics describes alterations in genomic function, mainly mitotically heritable changes in gene expression that occur through reversible chemical modifications of the structure of chromatin, without altering the DNA sequence. ${ }^{30,31}$ For example, certain cases of twin discordance might tially be stochastic in origin; however, because the causal mechanisms are not thoroughly understood, it is difficult to separate these mechanisms from environmental effects and gene-environment interactions. ${ }^{31}$ This notion could also be related to $\mathrm{MIH}$; therefore, further studies are needed to investigate environmental influences and gene-environment interactions in $\mathrm{MIH}$.

The high worldwide prevalence of MIH makes it a potential public health problem that has an impact on society. In addition to the clinical conditions associated with MIH, such as dental caries and hypersensitivity, and the greater need for treatment, studies have shown that this condition has a negative impact on quality of life and the aesthetic perception of children. ${ }^{32,33}$ Thus, MIH is relevant not only to the patient, but also to his family, the dentist, healthcare planners, policy makers and researchers. ${ }^{34}$

The authors believe that further knowledge about $\mathrm{MIH}$ is fundamental at both basic and clinical levels. Therefore, it is important for researchers to continue searching for answers to this enamel defect of such great challenge to clinical dental practice. ${ }^{4}$
Because of the limitation of the complex segregation analysis, our data could not determine the exact inheritance pattern, even though AIC values suggested the codominant model as the most probable pattern of inheritance of MIH. Moreover, according to Jarvik, ${ }^{28}$ there is no reliable approach to calculate the statistical power needed to detect the Mendelian pattern using this method. However, large-sized families could reduce the size of the needed sample, by allowing an increase in the transmission information. ${ }^{28}$ To the authors' best knowledge, the present study enrolled the largest number of investigated families comprising members affected by $\mathrm{MIH}$.

In conclusion, the number of families studied leads us to infer that more than one gene is responsible for the development of MIH. Alternatively, the present data suggests that this phenotype pattern signals a genetically complex disease. Further studies in other ethnically diverse populations could confirm this finding, and could also better investigate the influence of genetic and environmental factors, as well as the epigenetic factors related to MIH.

\section{Ethical approval}

This study was conducted in compliance with the guidelines of the Declaration of Helsinki and was approved by the research ethics committee of FOAr-UNESP, under protocol number 45/10.

\section{Competing interests}

The authors certify that they have no commercial or associative interest that could represent a conflict of interest in connection with the manuscript.

\section{Acknowledgments}

This study had the support of Fapesp (São Paulo Research Foundation, Brazil - registration numbers 2010/18436-1 and 2011/13636-5). The authors are grateful to the patients and their families for their highly appreciated cooperation.

\section{References}

1. Weerheijm KL, Jälevik B, Alaluusua S. Molar-incisor hypomineralisation. Caries Res. 2001 Sep-Oct;35(5):390-1. https://doi.org/10.1159/000047479 
Jeremias F, Bussaneli DG, Restrepo M, Pierri RAG, Souza JF, Fragelli CMB, et al.

2. Soviero V, Haubek D, Trindade C, Da Matta T, Poulsen S. Prevalence and distribution of demarcated opacities and their sequelae in permanent 1st molars and incisors in 7 to 13-year-old Brazilian children. Acta Odontol Scand. 2009;67(3):170-5. https://doi.org/10.1080/00016350902758607

3. Jälevik B. Prevalence and diagnosis of Molar-Incisor- Hypomineralisation (MIH): a systematic review. Eur Arch Paediatr Dent. 2010 Apr;11(2):59-64. https://doi.org/10.1007/BF03262714

4. Lygidakis NA, Wong F, Jälevik B, Vierrou AM, Alaluusua S, Espelid I. Best clinical practice guidance for clinicians dealing with children presenting with Molar-Incisor-Hypomineralisation (MIH): an EAPD policy document. Eur Arch Paediatr Dent. 2010 Apr;11(2):75-81. https://doi.org/10.1007/BF03262716

5. Jeremias F, Souza JF, Silva CM, Cordeiro RC, Zuanon AC, Santos-Pinto L. Dental caries experience and Molar-Incisor Hypomineralization. Acta Odontol Scand. 2013 May-Jul;71(3-4):870-6. https://doi.org/10.3109/00016357.2012.734412

6. Petrou MA, Giraki M, Bissar AR, Basner R, Wempe C, Altarabulsi MB, et al. Prevalence of Molar-Incisor-Hypomineralisation among school children in four German cities. Int J Paediatr Dent. 2014 Nov;24(6):434-40. https://doi.org/10.1111/ipd.12089

7. Allazzam SM, Alaki SM, El Meligy OA. Molar incisor hypomineralization, prevalence, and etiology. Int J Dent. 2014;2014:234508. https://doi.org/10.1155/2014/234508

8. $\mathrm{Ng} \mathrm{JJ}$, Eu OC, Nair R, Hong CH. Prevalence of molar incisor hypomineralization (MIH) in Singaporean children. Int J Paediatr Dent. 2015 Mar;25(2):73-8. https://doi.org/10.1111/ipd.12100

9. Elfrink ME, Ghanim A, Manton DJ, Weerheijm KL. Standardised studies on Molar Incisor Hypomineralisation (MIH) and Hypomineralised Second Primary Molars (HSPM): a need. Eur Arch Paediatr Dent. 2015 Jun;16(3):247-55. https://doi.org/10.1007/s40368-015-0179-7

10. Alaluusua S. Aetiology of Molar-Incisor Hypomineralisation: a systematic review. Eur Arch Paediatr Dent. 2010 Apr;11(2):53-8. https://doi.org/10.1007/BF03262713

11. Silva MJ, Scurrah KJ, Craig JM, Manton DJ, Kilpatrick N. Etiology of molar incisor hypomineralization: a systematic review. Community Dent Oral Epidemiol. 2016 Aug;44(4):342-53. https://doi.org/10.1111/cdoe.12229

12. Crombie F, Manton D, Kilpatrick N. Aetiology of molar-incisor hypomineralization: a critical review. Int J Paediatr Dent. 2009 Mar;19(2):73-83. https://doi.org/10.1111/j.1365-263X.2008.00966.x

13. Kuscu OO, Sandalli N, Dikmen S, Ersoy O, Tatar I, Turkmen I, et al. Association of amoxicillin use and molar incisor hypomineralization in piglets: visual and mineral density evaluation. Arch Oral Biol. 2013 Oct;58(10):1422-33. https://doi.org/10.1016/i.archoralbio.2013.04.012

14. Vieira AR, Kup E. On the etiology of Molar-Incisor Hypomineralization. Caries Res. 2016;50(2):166-9. https://doi.org/10.1159/000445128

15. Loli D, Costacurta M, Maturo P, Docimo R. Correlation between aerosol therapy in early childhood and Molar Incisor Hypomineralisation. Eur J Paediatr Dent. 2015 Mar;16(1):73-7.

16. Oyedele TA, Folayan MO, Adekoya-Sofowora CA, Oziegbe EO, Esan TA. Prevalence, pattern and severity of molar incisor hypomineralisation in 8- to 10-year-old school children in Ile-Ife, Nigeria. Eur Arch Paediatr Dent. 2015 Jun;16(3):277-82. https://doi.org/10.1007/s40368-015-0175-y

17. Jeremias F, Koruyucu M, Küchler EC, Bayram M, Tuna EB, Deeley K, et al. Genes expressed in dental enamel development are associated with molar-incisor hypomineralization. Arch Oral Biol. 2013 Oct;58(10):1434-42. https://doi.org/10.1016/i.archoralbio.2013.05.005

18. Jeremias F, Pierri RA, Souza JF, Fragelli CM, Restrepo M, Finoti LS, et al. Family-Based Genetic Association for Molar-Incisor Hypomineralization. Caries Res. 2016;50(3):310-8. https://doi.org/10.1159/000445726

19. Bussaneli DG, Restrepo M, Fragelli CM, Santos-Pinto L, Jeremias F, Cordeiro RC, et al. Genes Regulating immune response and amelogenesis interact in increasing the susceptibility to Molar-Incisor Hypomineralization. Caries Res. 2019;53(2):217-27. https://doi.org/10.1159/000491644

20. Simmer JP, Hu JC. Dental enamel formation and its impact on clinical dentistry. J Dent Educ. 2001 Sep;65(9):896-905. https://doi.org/10.1002/i.0022-0337.2001.65.9.tb03438.x

21. Sun X. Segregation analysis using the unified model. methods Mol Biol. 2017;1666:233-56. https://doi.org/10.1007/978-1-4939-7274-6_12

22. Visscher PM, Hill WG, Wray NR. Heritability in the genomics era: concepts and misconceptions. Nat Rev Genet. 2008 Apr;9(4):255-66. https://doi.org/10.1038/nrg2322

23. Bochud M. Estimating heritability from nuclear family and pedigree data. Methods Mol Biol. 2017;1666:195-210. https://doi.org/10.1007/978-1-4939-7274-6_10

24. Weerheijm KL, Duggal M, Mejàre I, Papagiannoulis L, Koch G, Martens LC, et al. Judgement criteria for molar incisor hypomineralisation $(\mathrm{MIH})$ in epidemiologic studies: a summary of the European meeting on $\mathrm{MIH}$ held in Athens, 2003. Eur J Paediatr Dent. 2003 Sep;4(3):110-3.

25. Akaike H. A new look at the statistical model identification. IEEE Trans Automat Contr. 1974;19(6):7. https://doi.org/10.1109/TAC.1974.1100705 
Inheritance pattern of molar-incisor hypomineralization

26. Kühnisch J, Thiering E, Heitmüller D, Tiesler CM, Grallert H, Heinrich-Weltzien R, et al. Genome-wide association study (GWAS) for molar-incisor hypomineralization (MIH). Clin Oral Investig. 2014;18(2):677-82. https://doi.org/10.1007/s00784-013-1054-8

27. Fatturi AL, Menoncin BL, Reyes MT, Meger M, Scariot R, Brancher JA, et al. The relationship between molar incisor hypomineralization, dental caries, socioeconomic factors, and polymorphisms in the vitamin D receptor gene: a population-based study. Clin Oral Investig 2020 Mar; https://doi.org/10.1007/s00784-020-03263-y

28. Jarvik GP. Complex segregation analyses: uses and limitations. Am J Hum Genet. 1998 Oct;63(4):942-6. https://doi.org/10.1086/302075

29. Souza JF, Gramasco M, Jeremias F, Santos-Pinto L, Giovanini AF, Cerri PS, et al. Amoxicillin diminishes the thickness of the enamel matrix that is deposited during the secretory stage in rats. Int J Paediatr Dent. 2016 May;26(3):199-210. https://doi.org/10.1111/ipd.12184

30. Godfrey KM, Lillycrop KA, Burdge GC, Gluckman PD, Hanson MA. Epigenetic mechanisms and the mismatch concept of the developmental origins of health and disease. Pediatr Res. 2007 May;61(5 Pt 2):5R-10R. https://doi.org/10.1203/pdr.0b013e318045bedb

31. Czyz W, Morahan JM, Ebers GC, Ramagopalan SV. Genetic, environmental and stochastic factors in monozygotic twin discordance with a focus on epigenetic differences. BMC Med. 2012 Aug;10(1):93. https://doi.org/10.1186/1741-7015-10-93

32. Fragelli C, Barbosa TS, Bussaneli DG, Restrepo M, Cordeiro RC, Santos-Pinto L. Aesthetic perception in children with molar incisor hypomineralization. Eur Arch Paediatr Dent. 2020 Jun; https://doi.org/10.1007/s40368-020-00541-x

33. Dantas-Neta NB, Moura LF, Cruz PF, Moura MS, Paiva SM, Martins CC, et al. Impact of molar-incisor hypomineralization on oral healthrelated quality of life in schoolchildren. Braz Oral Res. 2016 Oct;30(1):e117. https://doi.org/10.1590/1807-3107BOR-2016.vol30.0117

34. Schwendicke F, Elhennawy K, Reda S, Bekes K, Manton DJ, Krois J. Global burden of molar incisor hypomineralization. J Dent. 2018 Jan;68:10-8. https://doi.org/10.1016/i.jdent.2017.12.002 